\title{
INVISIBILIA: RELATO DE EXPERIÊNCIA SOBRE UM MATERIAL ALTERNATIVO PARA O ENSINO DE FILOSOFIA
}

\section{INVISIBILIA: AN EXPERIENCE REPORT ABOUT A ALTERNATIVE MATERIAL FOR PHILOSOSPHY TEACHING}

\author{
Taís Silva Pereira
}

Recebido em: 07/2020

Aprovado em: 08/2020

\begin{abstract}
Resumo: O baixíssimo número de filósofas presentes nos livros didáticos fornecidos pelo Programa Nacional do Livro Didático (PNDL) pode levar estudantes de todo o país à conclusão errônea de que não há pensadoras ao longo da história da filosofia, ou apenas que elas estão restritas às discussões contemporâneas. A fim de contribuir localmente para suprir em alguma medida esta lacuna na formação do ensino médio, foi elaborado o jogo de tabuleiro Invisibilia: em busca das mulheres na Filosofia. O jogo, fruto de uma produção coletiva entre professora, alunas e alunos, buscou apresentar diferentes filósofas que auxiliam os participantes a retirar cooperativamente os intolerantes do "jogo democrático" e concluir missões a respeito das lutas pela igualdade de gênero em um mundo desigual ou de inclusão precária, possibilitando um espaço comum de interação e também de reflexão. Produzido em 2018, o jogo faz parte do acervo de produtos educacionais no CEFET/RJ, já foi jogado em outros espaços formativos e seu material é acessível na internet. Este artigo pretende fazer um relato de experiência da elaboração e recepção do jogo Invisibilia, tendo em vista tanto a problematização acerca da ausência de filósofas nos livros didáticos e/ou paradidáticos - desde um recorte mais específico -, bem como uma investigação sobre a desigualdade estrutural de gênero, desde uma abordagem filosófica mais ampla. Decerto, tais níveis de análise (específico e amplo) estão sempre no horizonte de qualquer produção educacional que tenha um recorte de gênero e não podem ser deixados à margem desta investigação.
\end{abstract}

Palavras-chave: Mulheres; Ensino de Filosofia; Jogos; Produto Educacional.

\begin{abstract}
The smallest number of women philosophers in the textbooks offered by National Program of Textbook could lead students from all over the country to a erroneous conclusion of the women thinkers absence throughout Philosophy history, or at least that they are limited to the contemporary discussions. In order to supply this gap in the high school formation, a educational game called "Invisibilia: looking for the women in philosophy" was developed. The game, as a result of colective product between students and teacher, has aimed to present different women philosophers that help the participants to remove, in cooperative way, the intolerants from the "democratic game" and to conclude missions about the struggles of gender equality in a world of inequality or with precarious inclusion, enabling a common space of interaction and reflexion. The game was produced in 2018 and is part of educational products collection at CEFET/RJ, it is played in other spaces of formation and its material is available for free in a website. This paper intends to do an experience report on the elaboration and reception of the game "Invisibilia", in view of as the
\end{abstract}

\footnotetext{
${ }^{1}$ Doutorado em Filosofia. Professora EBTT do Centro Federal de Educação Tecnológica Celso Suckow da Fonseca - CEFET/RJ. E-mail: pereira_tais@yahoo.com.br
} 
problematization about the women philosophers absence in the textsbooks - from a specific frame - as an investigation about the genre estrutural inequality - from a wider philosophical approach. In fact, these levels (specific and wide) are always on the horizon of any educational production with a genre outline and they should not be left on this investigation.

Keywords: Women; Philosophy teaching; games; educational product.

\section{Introdução}

A presença da filosofia na escola, desde a lei 11.684/2008 (BRASIL, 2008) até a reforma do ensino médio instituída pela lei 13.415/2017 (BRASIL, 2017a), contribuiu para o aumento das produções dedicadas a estudantes no âmbito da educação básica, e igualmente para o amadurecimento das discussões sobre as possibilidades de materiais no horizonte da pluralidade de fazer, ensinar e aprender filosofia. Dentre as contribuições, mas não somente, destaca-se o crescimento de oferta de livros pelo Programa Nacional do Livro Didático, cuja primeira participação da Filosofia como disciplina iniciou-se em 2012, com a oferta de três livros, e em sua última edição, em 2018, contou com oito exemplares bastante diversificados quanto à disposição dos objetos de conhecimento, metodologia e forma de apresentação da filosofia. O impacto de um programa de distribuição de livros e manuais para o Brasil é bastante significativo, já que em algumas escolas e espaços formativos, o livro didático pode ser o único produto disponível para estudantes e o primeiro contato com a Filosofia. Ademais, sua presença ter um caráter indutor no currículo das escolas e nos processos seletivos para as universidades, como o Exame Nacional do Ensino Médio (ENEM).

A despeito do crescimento das obras selecionadas pelo PNLD, é possível averiguar a manutenção de um baixíssimo número de pensadoras nos livros didáticos para o ensino médio, mantendo-se entre 3\% a 4\% do número de totalidade de citações. Tal discrepância pode levar os estudantes a uma conclusão errônea sobre a presença de mulheres ao longo da história de filosofia - mesmo se fizermos um recorte da história da filosofia no ocidente - e restringi-las à contemporaneidade.

Foi, pois, diante da necessidade de se resgatar o lugar das pensadoras no cânone filosófico para estudantes do CEFET/RJ que se elaborou o jogo didático "Invisibilia: em busca das mulheres na filosofia". O jogo de tabuleiro, pensado no interior do projeto de extensão "A filosofia na construção de jogos", foi uma produção coletiva de alunos do $3^{\circ}$ e $4^{\circ}$ anos do ensino médio e professora, para a Semana Nacional da Ciência e Tecnologia de 2018, cujo tema orientador foi "Ciência para a redução das desigualdades". Ao assumir que o combate às desigualdades passa também pela visibilização de grupos que estão excluídos ou incluídos 
precariamente na sociedade, o jogo foi uma resposta possível para fortalecer a divulgação do pensamento de mulheres na filosofia e também de pensar novos usos de materiais para serem trabalhados na sala de aula.

Neste sentido, o presente artigo pretende realizar um relato de experiência da produção e aplicação do jogo, com base em uma investigação sobre a desigualdade estrutural, bem como o contexto das discussões sobre a construção de produtos educacionais em âmbito local. A fim de melhor embasar o relato, o texto se organizará em três seções, quais sejam: 1. Análise da desigualdade quanto aos modos de opressão e objetificação estruturalmente operantes nas sociedades e que impactam a produção acadêmica e didática na área da filosofia; 2. Problematização da utilização de outros materiais como alternativa aos livros didáticos, tendo em vista a ausência das mulheres (quantitativa e qualitativa) e, por fim, 3. Avaliação da produção de "Invisibilia", sua aplicação e recepção do público ao qual foi apresentado.

\section{Opressão e objetificação: entre a exclusão e a inclusão precária}

Compreender a ausência de mulheres nos livros didáticos requer a retomada da questão no quadro mais amplo acerca da invisibilidade de gênero como expressão concreta de modos de opressão e objetificação, marcados pelo sentimento de injustiça. Focar nestes dois conceitos é proveitoso porque ambos apontam tanto para a desigualdade, enquanto invisibilização e silenciamento, mas também para a inclusão precária, como o atendimento pontual, sem garantir ou mesmo considerar as condições para enfrentar a desigualdade efetiva. Ambas, a exclusão e a inclusão precária, são pensadas à luz do enraizamento da marginalização das mulheres, enquanto um grupo social, a despeito dos dispositivos formais e legais para a promoção da assimetria de gênero. Por grupo social, aqui, entende-se, seguindo a linha de Iris Young,

Grupos sociais [...] não são simplesmente coleções de pessoas porque eles são mais fundamentalmente entrelaçados com as identidades das pessoas descritas como pertencentes a eles. Eles são um tipo específico de coletividade, com consequências específicas no modo como pessoas entendem umas às outras (YOUNG, 1990, p. 43, tradução nossa)

Dois elementos desta definição são relevantes para os propósitos desta análise. O primeiro diz respeito à contraposição entre grupo social e somatório de indivíduos porque o que está em jogo não é a convergência de interesses particulares; antes, o grupo social depende de uma relação de pertencimento co-constituída pessoal e socialmente reconhecida. Por isso, não 
é uma espécie de associação entre pessoas que possuem os mesmos projetos, desejos, etc. Antes, há uma expectativa social de sua atuação que delimitam indivíduos a determinado grupo. Todavia, isto não implica afirmar um determinismo externo porque os indivíduos possuem agência, isto é, enquanto agentes assumem cursos de ação frente às possibilidades e restrições ao seu próprio modo. Esta imbricação entre agência e pertencimento está, pois, presente na definição de grupo social e auxilia trazer à tona o que está subjacente às normas, regulamentações e valores, bem como considerar as ações sempre em relação a outrem. Neste sentido, o segundo elemento presente na compreensão de grupo social que merece destaque é o conceito de identidade. A identidade de uma pessoa, afirma Young (2000, p. 102), também não é um somatório de afinidades de gênero, raça, classe e cultura, mas modos possíveis de assunção de si diante de uma configuração da qual não se escolhe - pessoas se constituem a partir de diversos grupos sociais, uns mais outros menos intensamente. Em outros termos, é a relação imbricada entre formação de si e condições que a atravessam, na relação com os demais, que perfazem quem se é. Diferentemente de tomar um grupo social como uma identidade fechada em si mesma, recorre-se, aqui, a sua construção relacional. As pessoas se autodefinem em relação a uma estrutura social compartilhada por hábitos, regulamentações, expectativas e pressuposições ${ }^{2}$.

A principal implicação desta concepção é marcar que as condições estruturais promovem ou impedem indivíduos a realizarem planos ou terem acesso a determinadas prerrogativas. Por estarem posicionadas em estruturas sociais diferentes, experiências e relações sociais são diferentes entre as pessoas, que muitas vezes são derivadas de desigualdades. As desigualdades estruturais privilegiam determinadas pessoas a despeito de outras. Young denomina opressão o modo como tais desigualdades operam socialmente. Para ela, a

Opressão neste sentido é antes estrutural do que o resultado de escolhas e políticas de umas poucas pessoas. Suas causas estão incorporadas em normas inquestionadas, hábitos e símbolos, nas suposições subjacentes às regras institucionais e consequências coletivas de se seguir estas regras (YOUNG, 1990, p. 41, tradução nossa).

Opressões se aplicam a grupos sociais e não são ações intencionais, se constituindo no entrelaçamento de suposições compartilhadas socialmente que alimentam situações de

\footnotetext{
${ }^{2}$ Inclusive, é por isto que a filósofa se distancia do que seria uma "política da identidade" para uma "política da diferença", ao partir do pressuposto de que as questões políticas referentes às lutas e demandas pela igualdade dizem respeito às diferentes experiências sociais de injustiça.
} 
desigualdade. Segundo a autora, é possível verificar, tendo como base os movimentos sociais da década de 1970 nos Estados Unidos, cinco modos de opressão, relativos a grupos específicos. São eles: exploração (relativa às relações de classe no contexto do capitalismo pós-industrial); marginalização (diz respeito sobre privação de condições materiais e de oportunidades); desempoderamento (forma adicional de exploração que traça uma linha entre condições respeitáveis e não respeitáveis de trabalho); imperialismo cultural (imposição do padrão de um grupo dominante sobre o outro) e violência (destruição de outrem sem nenhum motivo). Entendidos como uma família de conceitos e de condições, os modos de opressão perpassam experiências de injustiça de grupos sociais diferentes: referente à classe, gênero, raça, cultura, trabalho ${ }^{3}$.

Embora não caiba aqui uma análise mais detida às "faces da opressão", é importante frisar suas implicações referentes não apenas à exclusão (sendo a violência o exemplo mais radical), mas a formas precárias de inclusão. Assim como o fato de ser legalmente permitido a mulheres e homens realizarem atividades laborais, a discrepância entre renda e condições de trabalho para ambos são profundamente diferentes (seja quanto à desvalorização do trabalho doméstico, seja quanto aos postos de trabalho para pessoas trans, dentre outros). Há, desta forma, uma expectativa socialmente enraizada que alimenta práticas de opressão, as quais sobrevivem à formulação das regras formais. A inclusão não é efetivada porque há condições anteriores que travam sua realização. Como será mencionado mais adiante, este é um traço marcante nos livros didáticos de filosofia para o ensino médio, cuja presença das pensadoras, com raras exceções, se dá de forma marginal nos materiais.

Além do conceito de opressão, o conceito de objetificação pode ser proveitoso para pensar as nuances da desigualdade $\operatorname{social}^{4}$, na medida em que guarda seu caráter relacional. Em linhas gerais, a objetificação diz respeito a definições de imagens estereotipadas para manutenção do controle sobre determinados grupos. Tais imagens, positivas ou negativas ${ }^{5}$,

\footnotetext{
${ }^{3}$ A compreensão da autora a respeito da opressão considera que indivíduos são reconhecidos em diferentes grupos sociais e diferentes grupos sociais podem sofrer diversos modos de opressão. Inclusive, negros e mulheres, segundo Young, seriam os grupos que mais são alvos de opressão.

${ }^{4} \mathrm{O}$ conceito de objetificação é tema de grande debate nas teorias feministas, sobretudo as complexas discussões sobre pornografia (cf. PAPADAKI, 2020). A argumentação, aqui, toma o conceito no interior das desigualdades sociais e experiências de desrespeito, assumindo que a pornografia pode ser mais uma expressão destas desigualdades. Neste sentido, o conceito analisado também se afasta de uma consideração mais ampla de objetificação, tomada em diversos sentidos, inclusive com consequências positivas (quando precisamos de um serviço oferecido por outra pessoa, por exemplo uma consulta médica para o tratamento de uma doença, tratamola como um meio para atingir um fim determinado, mas não a diminuímos em sua humanidade, seu valor enquanto pessoa), tal como defendido na exposição de Nussbaum (1995).

${ }^{5}$ Patricia Collins (2016), sobre a diferença de processos de objetificação em mulheres brancas e negras, ressalta a importância de ser crítica com respeito à substituição de imagens estereotipadas negativas de negras por positivas,
} 
cristalizariam as possibilidades de autodefinição e autoavaliação sob o padrão de um grupo dominante. Significa afirmar, em outros termos, que a objetificação é moralmente prejudicial na medida em que impede a promoção da pessoa em sua singularidade. A este respeito, define Papadaki:

Objetificação é considerar e/ou tratar uma pessoa como objeto (considerar e/ou tratá-la em uma ou mais destas sete formas: como um instrumento, inerte, substituível, violável, dominada, negar sua autonomia, negar sua subjetividade), de tal forma que nega sua humanidade. A humanidade de uma pessoa é negada quando ela é ignorada/não propriamente reconhecida e/ou quando é em alguma medida prejudicada (PAPADAKI, 2010. p. 32, tradução nossa).

As formas elencadas por Papaki são retomadas da análise de Nussbaum (1995) a respeito das formas de objetificação. Mas, diferentemente desta última, Papadaki as considera em um nível mais restrito, voltado ao valor da pessoa, em termos de dignidade. Ademais, segundo a pensadora, a objetificação pode se dar em dois níveis (PAPADKI, 2010. p. 32-33): de forma intencional - quando aquele que torna outro um objeto o faz com propósito - e de forma não intencional - quando não há diretamente o propósito de negar ou não reconhecer a pessoa enquanto tal. Esta distinção é interessante quando voltamos ao ponto da desigualdade estrutural, isto é, as condições que limitam ou excluem grupos sociais. Neste sentido, se um homem se coloca na posição de intervir sobre a carreira mais adequada para sua parceira, por exemplo, ele pode fazer com base em uma natureza feminina mais emocional, condizente com atividades de cuidado. Embora seja uma forma de objetificação, ela não pode ser não intencional, porque seu objetivo não é tratar sua parceira como um objeto, mas (com base nos preconceitos de uma sociedade patriarcal) é antes assumir certos estereótipos sem refletir sobre eles. A não intencionalidade da objetificação contribui para uma melhor compreensão da complexidade de imagens estereotipadas de mulheres subjacentes a atitudes, hábitos e normas. Ainda segundo a autora, a objetificação pode ser redutiva e não redutiva. No primeiro caso, é uma objetificação que reduz ou prejudica a capacidade racional da pessoa objetificada; no segundo caso, essa capacidade é simplesmente ignorada e/ou não reconhecida. Se recorrermos ao mesmo exemplo supracitado, a objetificação seria do tipo não-redutiva ao não reconhecer as aptidões, desejos, capacidades, pessoais em nome de uma essencialização.

Ainda que Papadaki analise o conceito de objetificação com ênfase no não reconhecimento e/ou na negação de capacidades racionais, na esteira do conceito de autonomia

em geral destinadas a mulheres brancas, porque em ambos os casos as relações de dominação permanecem. 
kantiano vinculado à ideia de um ser humano tomado como fim em si mesmo, é possível situar a análise da autora a partir das relações sociais estruturais apontadas por Young, porque podemos negar a capacidade de agir por si de muitos modos, muitos deles não explícitos. Tanto o conceito de opressão quanto o de objetificação podem ser mobilizadores para o enfrentamento à exclusão das mulheres nos materiais didáticos e na própria formação filosófica de uma maneira geral. E é a este ponto que nos dedicaremos a seguir.

\section{Iniciativas de visibilização: os produtos educacionais alternativos}

Dos últimos livros lançados pelo $\mathrm{PNLD}^{6}$, em 2018, a presença das filósofas é muito menor se comparada aos filósofos homens, concentrando-se principalmente em nomes como Hannah Arendt e Simone de Beauvoir. Além da assimetria em termos quantitativos, há uma discrepância qualitativa, quanto ao tratamento das pensadoras nas obras. Poucas são referenciadas com box explicativos sobre sua biografia, por exemplo. Em alguns livros didáticos, algumas são mencionadas superficialmente sem conexão direta com o conteúdo do capítulo, ou apenas como referências de filmes e outras obras secundárias. Decerto, tal levantamento pode ser compreendido a partir dos conceitos de opressão e de objetificação. Primeiro porque a ausência ou a inclusão precária das mulheres nos livros não é fruto de uma intencionalidade organizada dos autores específicos, mas repousa na naturalização da assimetria de gênero em relação à produção de conhecimento e em relação ao exercício filosófico. O imperialismo cultural, enquanto modo específico de opressão, pode ser retomado aqui: não há mulheres na história da filosofia (ou pelo menos antes da modernidade tardia) porque suas obras não são referenciadas a partir de um critério masculino anterior, que as nega e/ou não reconhece como fonte. De forma análoga, a objetificação das mulheres a partir de imagens estereotipadas contribui com a discrepância na medida em que, de forma implícita, muitas vezes não há o reconhecimento da mulher enquanto filósofa, ou que pudesse formular um pensamento autônomo em diferentes períodos da história.

Em todos os livros didáticos do PNLD 2018, seguiu-se a recomendação de inserção de pensadoras, mas tal inclusão ainda foi bastante precária. É neste sentido que Wuensch (2015) classifica as mulheres como párias - dos cânones acadêmicos e currículos escolares - uma

\footnotetext{
6 As informações gerais das obras e suas respectivas resenhas estão disponíveis no link: https://www.fnde.gov.br/pnld-2018/index.html. Não é objetivo deste texto se concentrar em uma análise sobre a ausência das filósofas nos livros didáticos propriamente. Para uma discussão sobre este ponto, cf. ARAÚJO, 2019 e GABRIEL, 2019. Ambos os autores constatam que em relação ao total de pensadores citados, as mulheres correspondem a uma média de a $3 \%$ a $4 \%$ da totalidade de referências.
} 
condição de sem lugar, sem reconhecimento: "para que a existência de pensadoras não se resuma a um dado que se esgote no fato da vida de alguém, é preciso memória, narrativa e reflexão". (WUENSCH, 2015. p. 120).

Que esta produção de memória e resgate de narrativas não se encerram nos livros didáticos ou nos cursos oferecidos pelas universidades é evidenciada pelos projetos voltados para divulgação, popularização, tradução e pesquisas de e sobre filósofas, seja em âmbito universitário, seja no âmbito da educação básica por meio especialmetne de ações de pesquisa, e extensão ${ }^{7}$. Voltado para diversos públicos e com propósitos distintos, a variedade das produções sinaliza os espaços a serem ocupados e redefinidos.

Especificamente sobre a produção voltada para o público do ensino médio, ela se insere no interior de iniciativas e demandas locais, na comunidade escolar (como o próprio jogo a ser apresentado), e são mais difíceis de serem rastreadas e reunidas. Assim, o registro destas iniciativas perde-se em comunicações acadêmicas ou eventos escolares e depende, sobretudo, de publicações abertas a relatos de experiência, bem como repositórios para divulgação das atividades realizadas. A produção de materiais complementares e/ou alternativos aos livros didáticos, por depender de contextos específicos, ofereceria um mapeamento, inclusive, sobre como a ausência/presença das mulheres na filosofia é sentida e refletida em diferentes espaços escolares.

Importante ressaltar que por produto educacional entende-se a elaboração, adaptação e atualização de diferentes materiais de mediação para a realização de ações de ensinoaprendizagem frente a um público específico. Neste sentido, não apenas o texto corresponde a esta definição, mas também atividades de divulgação, investigativas, lúdicas e culturais, dispositivos digitais, filmes, dentre outros, podem igualmente ser concebidos como produtos educacionais. Isto implica afirmar que eles respondem a finalidades diferentes - seja para sensibilização, seja para problematização, seja para proposição, individual ou coletiva, dependendo em boa medida de um posicionamento quanto ao que se ensina e ao que se aprende no espaço formativo ao qual está inserido. Nos espaços escolares o lugar plural do produto educacional autoral, de docentes ou mesmo coletiva entre docentes e discentes, é particularmente importante para intervir pedagogicamente em contextos específicos sobre elementos e discussões que escapam aquelas oferecidas pelo livro didático.

Se voltarmos ao ponto levantado por Wuensch acerca da produção de memória,

\footnotetext{
${ }^{7}$ Parte deste acervo de projetos que envolvem o estudo de gênero na filosofia pode ser encontrado no portal Rede Brasileira de Mulheres filósofas: https://www.filosofas.org/projetos
} 
narrativa e reflexão, indo além da constatação da existência de mulheres na filosofia, a sala de aula tem um potencial de reconstrução do cânone filosófico em seus próprios cursos, apontando para dois elementos interconectados. O primeiro diz respeito ao critério de legitimação das fontes e autores que perfazem as discussões em torno do "clássico". Decerto, a inserção de mulheres na história da filosofia remete às formas de fazer filosofar quando os espaços de legitimação do conhecimento, como a universidade por exemplo, lhe eram negados por séculos. Com efeito, a presença de pensadoras acarreta a apreciação sobre o que faz uma questão ser filosófica e como devemos encaminhá-la metodologicamente.

O segundo elemento, inseparável do anterior, diz respeito à pluralidade da filosofia $\mathrm{e} o$ processo aberto de sua construção histórica. Ao deslocar o critério de legitimidade de um currículo dominado por homens, evidenciam-se condições de opressão e objetificação (explicitados anteriormente) que só podem ser manifestas pelas párias, ou seja, pelos grupos sociais que passam pela experiência do desrespeito. As pensadoras, na medida em que pensam e escrevem desde este sem lugar do cânone, no lugar de "outras", promovem novas possíveis articulações conceituais que fogem ao currículo tradicional e recompõem tradições. Acrescentese a isto o fato de que a sala de aula na educação básica é um espaço bastante profícuo para estes deslocamentos e atualizações, pois seu público não é constituído por filósofos ou futuros filósofos profissionais. Neste sentido, a própria relação com a filosofia se dá de diferentes modos entre os jovens do ensino médio em diálogo com outras disciplinas e vivências do processo formativo.

É, pois, com base nestas análises preliminares sobre a desigualdade e inclusão precária no interior da produção educacional para o ensino de filosofia que o jogo Invisibilia se insere. Enquanto um produto educacional lúdico, propõe-se a trazer à tona questões e conceitos da filosofia política de modo interativo e prazeroso, com o auxílio de diversas pensadoras ao longo da história da filosofia. Seu público-alvo é primordialmente de estudantes do ensino médio e o público em geral que se interesse pelo tema. A seguir, faremos o relato de experiência da produção, aplicação e avaliação do jogo.

\section{Invisibilia: em busca das mulheres na filosofia - relato de experiência}

O jogo "Invisibilia" ${ }^{8}$ foi produzido pelo grupo de extensão "A filosofia na construção

\footnotetext{
${ }^{8}$ Este jogo não seria possível sem a participação árdua e divertida do grupo de extensão no ano de 2018: Natalia Pires da Costa, Jaqueline de Andrade Correia, Victoria Crystina Freitas da Silva, Felipe Jaña Laucas de Campos e
} 
de jogos", cadastrado no CEFET/RJ desde 2013, tendo como objetivo criar coletivamente jogos educacionais voltados para o ensino de filosofia no ensino médio e para a divulgação do saber filosófico entre o público geral. Assim, ele é produzido por alunos e se destina principalmente para alunos, em sala de aula. Seu protótipo, concluído em setembro de 2018, foi apresentado na Semana Nacional de Ciência e Tecnologia, cujo tema foi "Ciência para a redução das desigualdades" e também se inspirou no tema da 6 a Olimpíada Estadual de Filosofia do Rio de Janeiro, ocorrida na cidade de Volta Redonda, intitulada “Outras vozes”. Desta forma, a questão da desigualdade de representatividade pensada a partir dos dispositivos de opressão e objetificação esteve presente em todo o processo de elaboração pelo grupo.

O desafio de elaboração de um jogo filosófico diz respeito principalmente à tradução de questões, teorias e conceitos em mecânicas de jogos, isto é, nas regras que perfazem a jogabilidade de forma atrativa, não se reduzindo a meros quizes de perguntas e respostas e tampouco jogos que dependam muito da sorte, como jogos de trilha. Ambos restringiriam um espaço de interação importante ora por se confundir com uma prova com opções previamente dadas e não permitindo sua rejogabilidade, ora por retirar o protagonismo dos participantes, que ficam dependentes da rolagem dos dados. Mesmo diante da vantagem de uma duração menor para sua execução, importante para o tempo de aula, as mecânicas supracitadas correm o risco de se tornarem mais fontes de informações a serem adquiridas do que a possibilidade de um espaço para discussão filosófica. Por este motivo, os jogos produzidos no projeto de extensão, do qual "Invisibilia" faz parte, assumem mecânicas de jogos modernos, isto é, jogos que priorizam estratégias e tomadas de decisão dos jogadores. Em geral, os jogos produzidos são de tabuleiro e/ou de cartas, com materiais que podem ser encontrados em papelaria. A produção dos jogos é concebida coletivamente, a partir da seguinte metodologia:

1. Definição do tema elou problema filosófico e mecânica do jogo: Neste momento, o grupo pensa o objeto a ser tratado no jogo, bem como o tipo de jogo a ser utilizado. Este passo é também um espaço de troca sobre o que sabemos e sobre o que consideramos importante para ser divulgado. Muitas vezes, os temas nascem de inquietações, curiosidade ou busca de aprofundamento sobre determinada questão.

No caso de Invisibilia, o grupo, formado por 4 alunos e 1 aluno que já tiveram filosofia em sala, se debruçou sobre a questão da ausência das mulheres no livro didático e em outros materiais recebidos durante sua experiência com a filosofia. Ao pensar sobre as filósofas que

Vitoria Abdalla, responsável pelas ilustrações do jogo. 
conheciam e/ou estudaram, apenas as pensadoras contemporâneas foram rapidamente listadas. As referências à Hannah Arendt, Angela Davis, Simone de Beauvoir e Judith Butler foram o ponto de partida para a pergunta se haveria mulheres em outros períodos da história da filosofia. Hipátia foi lembrada (graças a uma pesquisa em Física, não em Filosofia), mas não Diotima, cuja referência por Platão em $O$ banquete era parcialmente conhecida entre os integrantes. Diante da dificuldade de elegermos filósofas, ficou claro o tema do jogo, buscar e divulgar a presença de filósofas na história. Vale ressaltar que esta dificuldade não estava presente apenas para os alunos, mas igualmente para mim, docente, que conhecia pouquíssimas pensadoras fora do eixo europeu. Neste sentido, todo o grupo era igualmente ignorante sobre o tema, propiciando um ponto de partida comum. Quanto à mecânica, pensou-se em um jogo que envolvesse estratégia e que abordasse filosoficamente problemas políticos sobre a desigualdade social sofrida por mulheres mesmo em uma democracia contemporânea.

2. Testes com mecânicas de jogos modernos: Parte do processo de construção de um jogo educacional envolve a pesquisa de jogos comerciais que já existem no mercado e que possam inspirar as produções locais. Como não há direito autoral sobre mecânica de jogos, isto é, sobre as regras do jogo, é possível adaptar alguns jogos, desde que citadas as referências. "Invisibilia" foi inspirada em um jogo de tabuleiro cooperativo de aventura chamado "As lendas de Andor" (MENZEL, 2012). Com temática de fantasia medieval, narra a história de guerreiros que defendem o castelo de Andor das forças inimigas. Cada jogador interpreta um personagem que possui habilidades específicas e contribuem para o cumprimento de tarefas ao longo do jogo. Embora a sorte seja um elemento presente em Andor, ela não é predominante, permitindo que os participantes possam criar conjuntamente estratégias para os problemas que surgem ao longo do jogo. Foi este ponto que mereceu destaque para a construção de "Invisibilia". Jogar é uma experiência à parte no projeto. Primeiro porque ganha uma de transgressão, visto que jogos em geral ficam foram da sala de aula, e não dentro dela. Segundo, porque o grupo vai conhecendo diferentes mecânicas que podem ser articuladas para a produção de um novo jogo.

Assim, como em Andor, "Invisibilia" é um jogo de tabuleiro de aventura e cooperativo e podem jogar de dois a quatro grupos. No lugar de um reino medieval, temos uma cidade, Invisibilia, cujos representantes vêm mobilizando projetos de lei que entram em conflito com princípios democráticos, atingindo especialmente cidadãs mulheres, como por exemplo, restrições de vestimentas e locomoção, em nome da segurança. Situação apoiada por grupos crescentes de intolerantes que defendem a assimetria de gênero, a cidade sofre da chamada "tirania da maioria". Tais ações serão combatidas por um grupo de mulheres, que com o auxílio 
de filósofas, lutarão pela conquista da ética democrática baseada na igualdade e justiça. A narrativa inicial do jogo já coloca uma série de questões levantadas pela filosofia política e que podem ser trabalhadas antes, durante, ou mesmo depois da partida.

Cada grupo interpreta uma personagem livremente inspirada nas quatro filósofas contemporâneas lembradas pelo grupo: a biografia de Arendt ajuda na composição de Aisha, uma refugiada muçulmana sem direitos políticos que assegurem sua cidadania e por este motivo não pode circular livremente pela cidade de Invisibilia; Davis inspira a elaboração da personagem Jéssica, mulher negra e periférica, cujas condições materiais insuficientes e o preconceito dificultam o exercício de sua liberdade (por exemplo, ela não pode cortar caminho utilizando o metrô no jogo); Butler fornece a base para personagem de Dominique, militante LGBTQUIA+, alvo de muito preconceito em Invisibilia, e também sofre restrição à sua liberdade de percorrer o tabuleiro; por fim, Clara, livremente associada a Beauvoir, é uma professora universitária de classe média e mãe solo (por isso, uma de suas fraquezas é não jogar uma de três rodadas que compõem um dia no jogo em virtude de sua dupla jornada). Todas elas possuem habilidades e fraquezas distribuídas em três categorias: coragem, percepção e persuasão. A coragem é necessária para combater os intolerantes no jogo, já a percepção e a persuasão são importantes para a concussão das tarefas ao longo da partida. Encarnar a pele da personagem é proveitoso para a sensibilização dos dilemas de gênero, porque as habilidades e fraquezas de cada uma têm um impacto direto sobre as condições de jogo dos participantes. Assim, as regras do jogo interditam ludicamente a formação de si em cada personagem.

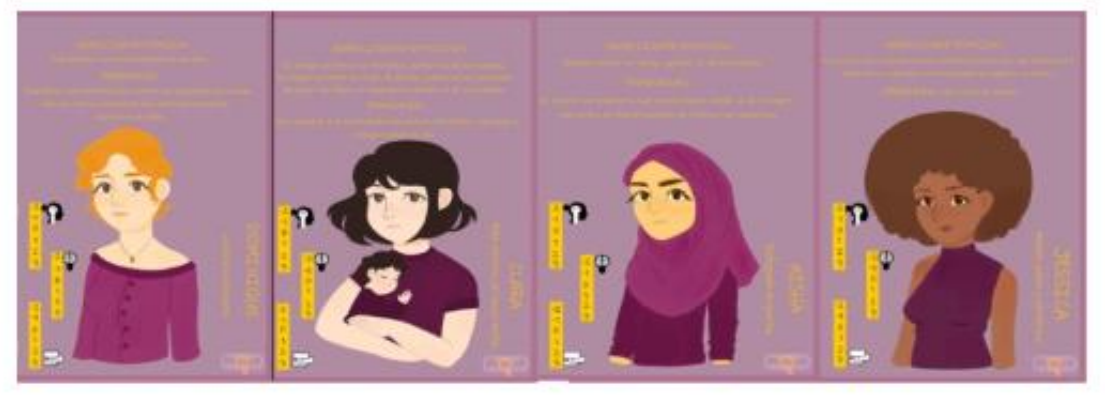

Figura 1. Personagens do iogo: Dominique, Clara, Aisha e Jessica.

Além das quatro personagens principais, o jogo conta com um pequeno baralho de 20 filósofas, com uma breve biografia e um benefício para ajudar nas tarefas a serem cumpridas e que surgem ao longo da partida. Os participantes precisam recorrer às chamadas "filósofasmadrinhas", em casas específicas do tabuleiro, para que possam ganhar a partida, por isso não 
podem ser ignoradas. É impossível jogar individualmente e é impossível prescindir das filósofas para a conclusão do jogo.

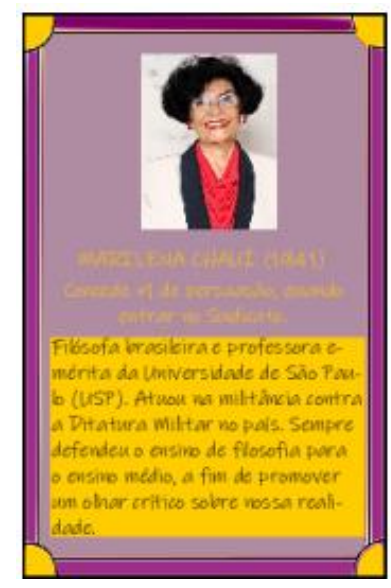

Figura 2: Exemplo de carta de filósofa-madrinha - Marilena Chauí

3. Levantamento de referências: Como o propósito do jogo foi conferir maior visibilidade a pensadoras de diferentes períodos da filosofia, mais do que se concentrar no pensamento de determinada autora, o grupo procurou delimitar obras mais gerais sobre a presença de filósofas e obras que tematizassem a opressão e a objetificação das mulheres. Os livros Filósofas: a presença das mulheres na filosofia (PACHECO, 2016) e Mulheres filósofas na história (GLEICHAUF, 2010), bem como o material, gentilmente fornecido por Ana Míriam Wuensch, em sua palestra no CEFET/RJ, constituíram o cerne da bibliografia selecionada.

4. Leituras e discussões das referências elencadas: Parte dos encontros constituiu-se da discussão da bibliografia e pesquisa, articulando-os com outras referências. As discussões do grupo foram imprescindíveis para a delimitação da narrativa do jogo.

5. Produção do manual: O momento mais desafiador de toda a metodologia de produção de jogos no projeto é a escrita do manual, quando o grupo precisa traduzir as leituras e discussões em livro de regras, acessível a jogadores que não estão familiarizados com conceitos e termos técnicos da filosofia. O princípio principal do projeto é formular jogos que possam ser jogados por quem se interessem em jogar, supondo que é possível reconhecer questões filosóficas porque passamos em alguma medida por experiências que, pelo menos, promovem o filosofar.

Os jogadores fazem parte do grupo de mulheres de Invisibilia, que está se mobilizando para impedir a promoção de leis antidemocráticas em seu país e também para acabar com a atuação de intolerantes na comunidade política. Para isto, utilizarão em conjunto suas 
habilidades de percepção, persuasão e coragem, com ajuda de filósofas-madrinhas. O objetivo do grupo é não deixar que os intolerantes cheguem ao Congresso, uma casa específica do tabuleiro, (tirá-los do "jogo democrático"), completar as tarefas com seus respectivos eventos e, até o término da partida, completar 12 pontos. Para combater os intolerantes, os participantes precisam ganhar na rolagem de dados. Como os intolerantes possuem 8 pontos de ódio, os jogadores precisam, juntos ou separados, somar mais que a pontuação deles. As filósofasmadrinhas podem tirar um intolerante do jogo e diminuir seus pontos de ódio, além de outros benefícios.

O jogo é divido em três missões interdependentes e que podem ser jogadas separadamente. Em média, cada missão dura 60 minutos. Por isso, o ideal é que seja jogado em dois tempos de aula. Cada missão explora mais diretamente alguns elementos presentes no currículo de Filosofia Política voltado para o ensino médio.

Missão 1:

Descrição: O primeiro projeto de lei, voltado para coibir a violência feminina, prevê restrições ao tipo de vestuário e locomoção de mulheres sozinhas em determinadas regiões com alto índice de assalto e estupro, a partir das $22 \mathrm{~h}$ e começa a ser debatido na Comissão de Ética. Algumas mulheres percebem que este é o melhor momento para tentar esclarecer a população sobre a incongruência da lei, ao restringir direitos básicos às mulheres e culpabilizar as vítimas. Ao mesmo tempo, grupos extremistas veem que a organização feminina irá gerar caos à convivência humana e, como guardiões da ordem, tentarão ocupar o congresso para que a mobilização não interfira nas discussões e futura aprovação das leis. Tarefa: $\mathrm{O}$ grupo terá 7 dias [21 rodadas] para convencer a população e a Comissão de ética sobre a injustiça das leis propostas. Para isso, precisará ter, no fim da missão, ter completado pelo menos 12 pontos de experiência [soma do cumprimento das tarefas e vitória no combate de intolerantes]. Conteúdos que podem ser trabalhados a partir do jogo: O sentido de política; constituição do Estado; lei e soberania; instituições; desigualdade estrutural; limites da tolerância.

Missão 2:

Descrição: A mobilização para o esclarecimento da população surtiu um efeito positivo em Invisibilia. A votação foi suspensa e alguns congressistas mostram-se favoráveis a revisar os projetos de lei. Embora haja a esperança de avanços, grupos de intolerantes, em nome da liberdade expressão, organizam-se para interromper a aproximação entre as mulheres e o congresso. Eles também procurarão aliados. Será necessário pensar em estratégias efetivas para impedir de vez as votações antidemocráticas. Tarefa: $O$ grupo terá 3 dias [9 rodadas] para se 
organizar, se encontrar com os congressistas e impedir o avanço dos intolerantes. Para isso, no fim da missão, o grupo precisa ter completado todas as missões e se encontrar no congresso. Se o grupo chegar ao congresso, deverá propor medidas que impeçam o avanço dos projetos de lei que estão em suspenso, em forma de debate aberto, mediado pelo professor/narrador. Conteúdos que podem ser trabalhos: Mobilização política; poder; debate público; esfera pública; limites da tolerância.

\section{Missão 3:}

Descrição: Apesar da abertura inicial de novos debates e do convencimento de alguns congressistas com o objetivo de impedir as leis antidemocráticas, grupos de intolerantes estão articulados e conseguem apoio mais amplo, utilizando o medo e a insegurança frente a uma suposta crise institucional. As mulheres temem que suas ideias sejam distorcidas e percebem que suas propostas só serão levadas a sério se contarem com o apoio irrestrito da população. Por isso, será hora de agir. Tarefa: $\mathrm{O}$ grupo terá 7 dias [21 rodadas] para organizar e realizar um movimento de resistência contra as ideias que alimentam a onda de intolerância em Invisibilia e, então, pressionar o Congresso a não votar os projetos de leis que afetam diretamente a igualdade e a justiça entre os seus habitantes. Conteúdos que podem ser trabalhados: Ação; poder e resistência

As missões 1 e 3 seguem o mesmo roteiro, a missão 2, por seu turno, tem uma dinâmica diferente. Além das tarefas e combate aos intolerantes, há o debate sobre os temas levantados ao longo do jogo. Este recurso surgiu da discussão dos participantes do projeto sobre a necessidade de se criar um espaço de discussão efetivo entre os jogadores e não restringir as discussões filosóficas inteiramente às regras do jogo. Este recurso se mostrou bastante profícuo porque, guardadas as devidas proporções, o espaço de interação aberto pelo jogo pode ser próximo aquele espaço do debate orientado por argumentos coerentes.

6. Confecção do jogo e testes de jogabilidade: O jogo é analógico, mas seu material está disponível no site do projeto e também pode ser pedido gratuitamente por e-mail ${ }^{9}$. É composto de 1 tabuleiro, representando a cidade de Invisibilia, 4 fichas com as personagens principais, além de 3 baralhos de missões (média de 19 cartas para cada baralho) e 1 baralho com 20 cartas de filósofas-madrinhas. No tabuleiro estão dispostos locais (congresso, biblioteca, escola, centro cultural, etc.) para os quais as personagens devem se dirigir e também o símbolo "phi", onde os jogadores podem sortear uma carta de filósofa-madrinha. São necessários também

\footnotetext{
${ }^{9}$ https://www.wix.com/dashboard/8874ecf5-503d-4f04-82e6-4c3ddb61067a/home O e-mail de contato do projeto é filosofiaejogos@gmail.com
} 
peças de movimentação e dados.

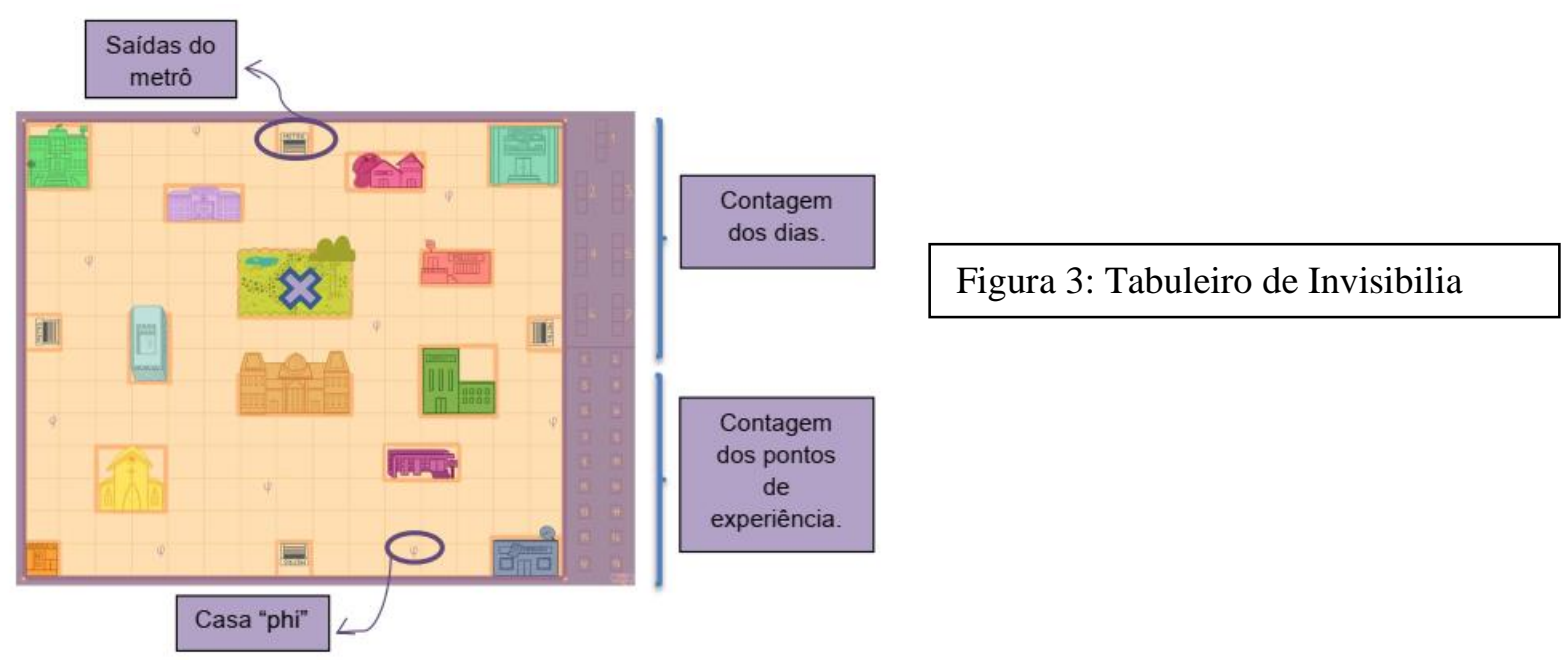

7. Testes de jogabilidade: Os testes de jogabilidade são realizados antes da versão final do jogo, preferencialmente com participantes externos ao grupo. Assim, é possível verificar possíveis inconsistências nas regras, além de uma primeira recepção e avaliação externa. Após o teste, o protótipo é encaminhado para apresentação na Semana Nacional de Ciência e Tecnologia, evento nacional presente nas universidades e escolas federais do país. Neste período, sempre no segundo semestre do calendário escolar, o CEFET/RJ promove minicursos e ciclo de palestras, atividades artísticas e culturais, trabalhos de pesquisa de nível médio e superior, exposição de trabalhos dos cursos técnicos internos e externos, dentre outros. É um período muito rico quando se tem a oportunidade de se vislumbrar as diversas atividades desenvolvidas na escola.

8. Apresentação do jogo: Invisibilia foi apresentado em quatro dias (turnos da manhã e da tarde) durante o evento, recebendo o público do CEFET/RJ e da comunidade externa. Por volta de 100 pessoas passaram pelo stand do projeto para conversar sobre o jogo, e em média 20 a 30 pessoas jogaram o jogo. Foi uma oportunidade de divulgação do jogo, mas também de conversar sobre a desigualdade de gênero. No geral, o protótipo foi bem recebido, ganhando inclusive sugestões de inserção de mais pensadoras. Ainda assim, houve reticências e resistências ao jogo, sobretudo pela incompreensão da temática e de sua importância para formação filosófica. Embora o grupo tivesse o cuidado de elencar filósofas de diversos períodos e correntes, eventualmente o jogo causou desconforto ou recusa entre alguns poucos homens adultos que não jogaram Invisibilia, mas pararam para ver o stand. A falta de compreensão sobre o significado e a importância de um recorte de gênero na educação, somada à condição 
sócio-política às vésperas da eleição presidencial, além da própria estrutura social que condiciona padrões patriarcais, podem ser aventados como possibilidades explicativas deste tipo de recepção. Além da Semana Nacional de Ciência e Tecnologia o jogo foi levado para o grupo de licenciatura em História, Ciências Sociais e Filosofia da UNIRIO, em março de 2019 e em maio do mesmo ano, na paralisação nacional de Educação, contra os cortes nas universidades públicas, "Invisibilia" também esteve presente na Praça XV, no centro do Rio de Janeiro. Na UNIRIO futuros educadores puderam avaliar o jogo e a troca foi bastante rica. A preocupação com a duração do jogo, por exemplo, foi um ponto importante, dado o exíguo tempo de aula em boa parte das escolas públicas e privadas (um tempo semanal de $50 \mathrm{~min}$.). No evento da Praça XV, embora os transeuntes não pudessem parar e jogar, em geral se mostraram interessadas no jogo e nos demais projetos do CEFET/RJ. Foi um momento importante para mostrar à população o que se faz na escola pública.

9. Avaliação do jogo e revisão do jogo: O processo de elaboração do jogo durou cerca de sete meses, entre a definição do tema e a primeira apresentação. Todo este processo foi marcado pela pressuposição do trabalho como princípio educativo, em que estudantes são protagonistas da produção de conhecimento, e a relação ensino-aprendizagem não é polarizada. Pode-se afirmar que o jogo Invisibilia: em busca das mulheres na filosofia cumpre com seu papel de evidenciar as ausências e silenciamentos das mulheres na história da filosofia enquanto produto educacional. Entretanto, devido sua atuação local, é apenas mais uma contribuição no âmbito da educação básica que não pode estar afastada da produção acadêmica e de políticas públicas favoráveis à discussão de gênero nas escolas. Traduções, artigos e demais materiais produzidos são imprescindíveis para a consolidação das pensadoras nos currículos escolares. O trabalho interdisciplinar, que une ensino, pesquisa e extensão certamente fará a diferença.

\section{Considerações finais:}

O relato de experiência, tão importante para divulgar o que se faz na escola, é sempre desafiador: ficamos na expectativa de reproduzir tudo o que se passou durante o processo da atividade apresentada. Mas, como diz Larrosa (2016), a experiência é aquilo que nos acontece e não pode ser confundida com informação e conhecimento. Ela acontece para aqueles que a vivenciaram. Todavia, toda experiência é situada em algo - questões, incômodos -, os quais se referem a conceitos e investigações sejam elas pretéritas ou projetadas para um futuro. Este relato, talvez um tanto incompleto, por não captar nuances fundamentais, mas fugidias do 
processo de ensino-aprendizagem, do estar e pertencer à escola, nem por isso é incomunicável. A proposta deste artigo foi relatar e, ao relatar, construir memória, de mulheres filósofas, pensadoras para a comunidade o CEFET/RJ, na esperança que elas possam habitar o currículo das escolas de nível médio e construir pontes e novas articulações na formação de estudantes e professores.

A construção do jogo, como produto educacional viável para a sala de aula, é atravessada por questões sobre modos de opressão e silenciamento que excluem ou incluem precariamente pensadoras no cotidiano da aprendizagem e que não podem ser deixadas de lado quando defendemos a problematização do cânone filosófico. Assim, a primeira parte nos ajuda a compreender o relato desde uma perspectiva mais ampla, apontando para as condições estruturais que precisam ser evidenciadas tendo em vista estratégias e ações refletidas. E, por isto a segunda parte deste artigo, uma ação possível é a criação de materiais complementares e/ou alternativos aos livros didáticos. Espera-se que a divulgação do trabalho empreendido pelo grupo de extensão do CEFET/RJ contribua localmente para suprir o espaço de existência e memória de filósofas.

\section{Referências}

ARAÚJO, Iron Mendes de. Em busca das mulheres na Filosofia: A participação das filósofas nos livros didáticos de Filosofia do Programa Nacional do Livro Didático - 2018. Recife: UFPB, 2019. Dissertação de mestrado profissional de Filosofia.

BRASIL, Lei ordinária 11.684 de 02 de junho de 2008. Altera o art. 36, de agosto de 2006, altera o artigo 10 da Resolução CNE/CEB n ${ }^{\circ} 3 / 98$, que institui as Diretrizes Curriculares Nacionais para o Ensino Médio. Diário Oficial da União. Brasília, 2006, seção 1, p. 15.

BRASIL. Lei ${ }^{\circ} 13.415$, de 16 de fevereiro de 2017a. Altera as Leis $n^{\circ} 9.394$, de 20 de dezembro de 1996, que estabelece as diretrizes e bases da educação nacional, e no 11.494 , de 20 de junho 2007, que regulamenta o Fundo de Manutenção e Desenvolvimento da Educação Básica e de Valorização dos Profissionais da Educação, a Consolidação das Leis do Trabalho CLT, aprovada pelo Decreto-Lei no 5.452, de 1 de maio de 1943, e o Decreto-Lei $\mathrm{n}^{\circ}$ 236, de 28 de fevereiro de 1967; revoga a Lei $\mathrm{n}^{\circ}$ 11.161, de 5 de agosto de 2005; e institui a Política de Fomento à Implementação de Escolas de Ensino Médio em Tempo Integral. Portal da Legislação. Brasília, 2017a. Disponível em <http://www.planalto.gov.br/ccivil_03/_Ato20152018/2017/Lei/L13415.htm>. Acesso em 25 de fevereiro de 2020.

BRASIL, Ministério da Educação. PNLD 2018: Filosofia - guia de livros didáticos - Ensino Médio. Brasília: Ministério da Educação: Secretaria de Educação Básica, 2017b. Disponível em <https://www.fnde.gov.br/pnld-2018/index.html>. Acesso em 20 de fevereiro de 2020.

COLLINS, Patricia Hill. "Aprendendo com a outsider within: a significação sociológica do 
feminismo negro". Trad. Juliana de Castro Galvão. In: Revista Sociedade e Estado, v. 31, n. 1, 2016. pp. 99-127.

GABRIEL, Alice de Barros. "Gênero nas aulas de Filosofia: Análise de um livro didático". In: Kínesis, v. XI, n. 28, julho de 2019, p. 1-14.

GLEICHAUF, Ingebord. Las mujeres filósofas en la historia: desde la antgüedad hasta el siglo XXI. Trad. Kátia Pago Cabanes. Barcelona: Icaria; LaDesclosa, 2010.

LARROSA, Jorge. Tremores: Escritos sobre experiência. Trad. Cristina Antunes e João Wanderley Geraldi. Belo Horizonte: Autêntica, 2016.

MENZEL, Michael. As lendas de Andor. Devir Brasil, 2012.

NUSSBAUM, Martha. "Objectification”. In: Philosophy and Public Affairs v. 24, n.4, 1995, pp. 256-57.

PACHECO, Juliana. (Org.). Filósofas: a presença das mulheres na filosofia. Porto Alegre: Editora Fi, 2016.

PAPADAKI, Lina. "What is is objectification?". In: Journal of Moral Philosophy. v. 7, n. 1, 2010. pp. 16-36.

. "Feminist Perspectives on Objectification". In: Edward N. Zalta (ed.). The Stanford Encyclopedia of Philosophy, Summer of 2020. Disponível em <https://plato.stanford.edu/archives/sum2020/entries/feminism-objectification/>. Acesso: 12 de julho de 2020.

PROJETOS: CONHEÇA OS TRABALHOS BRASILEIROS SOBRE FILOSOFIA E MULHERES. Rede Brasileira de Mulheres Filósofas. 2019. Disponível em < https://www.filosofas.org/projetos>. Acesso em 02 de julho de 2020.

WUENSCH, Ana Míriam. "Acerca da existência de pensadoras no Brasil e na América Latina", Problemata Revista Internacional de Filosofia. v. 6, n. 1, 2015. pp. 113-150.

YOUNG, Iris Marion. Justice and the politics of difference. Princeton, New Jersey: Princeton University Press, 1990.

Inclusion and democracy. Oxford: Oxford University Press, 2000. 